\title{
Remote Sensing to Minimize Energy Consumption of Six-axis Robot Arm Using Particle Swarm Optimization and Artificial Neural Network to Control Changes in Real Time
}

\author{
Somyot Kaitwanidvilai, Veerasak Chanarungruengkij, ${ }^{*}$ and Poom Konghuayrob \\ Faculty of Engineering, King Mongkut's Institute of Technology Ladkrabang, Bangkok 10520, Thailand
}

(Received May 9, 2019; accepted January 14, 2020)

Keywords: neural network, optimal energy, PSO, remote sensor, lean manufacturing

We propose a new method for the analysis and design of a robotic system that minimizes the energy consumption of a six-axis robot arm by controlling the velocity and acceleration of each arm of the robot to achieve the specified trajectory of the robot determined from a lean manufacturing method. A dynamic model of the PUMA 560 robot has been simulated on MATLAB, while the Robotics Toolbox and particle swarm optimization (PSO) are utilized to search for optimal paths and the optimal velocity and acceleration of the robot arms. The optimal velocity and acceleration are described as those giving minimum overall energy consumption constrained by a specified cycle time of the entire robotic system. Typically, the picking and placing of materials are carried out by humans, causing a variation in production rate, whereas our system using a robot arm ensures a stable production rate. Moreover, the optimal results obtained from PSO are adopted to train an artificial neural network (ANN) to extend the design system from discrete optimal values to a continuous and near-optimal value. In other words, the ANN is used to obtain an approximate optimal value between those obtained from PSO to make the system applicable to a real-world system. As shown by the simulation results, this method reduces the energy consumption of $12.3 \%$ from the initial energy and reduces the time for optimization by $99.8 \%$ compared with that for the PSO technique.

\section{Introduction}

Lean manufacturing techniques are used to improve the production process in factories. The improvement yields the most optimal time of the production process ${ }^{(1,2)}$ in terms of motion and production layout. To serve industry 4.0, the proposed method remotely controls the production parameters continuously, considering the time, cost, transportation cost, safety, and reliability. This system minimizes the amounts of all materials in the supply chain and reduces labor costs. ${ }^{(3-7)}$ Remote sensing has a number of applications such as detecting the temperature of electromagnetic compatibility (EMC) on aerospace platforms, ${ }^{(8)}$ wireless remote control to send data to a server for processing, ${ }^{(9)}$ and using a smartphone as a mobile gateway to send data from a sensor to a server for processing. ${ }^{(10)}$

*Corresponding author: e-mail: vee7713@gmail.com

https://doi.org/10.18494/SAM.2020.2428 
However, current production employs industrial robot (IR) arms for many tasks where the speed can be remotely controlled from anywhere. When using many robotic arms, energy must be considered because the energy cost is one of the main production costs. The total energy consumption in the industrial sector is $37 \%$ of the total energy consumption in the world. ${ }^{(11)}$ The automotive industry is one of the largest industries in the world. In the automotive industry, the energy consumption by IRs in the production line is about $8 \%$ of the total energy consumption $^{(12)}$ and the proportion is likely to increase in the future. The energy consumption of robots is of interest because it is a direct cost of business. For the above reasons, research and development to reduce the energy consumption of IR is important.

Many studies have been performed on hardware such as the type of robot arm that should be selected by considering energy consumption ${ }^{(13)}$ or electric energy loss from materials. ${ }^{(14)}$ There have also been many studies on software. For example, research on choosing the trajectory of a robot arm found that a parabolic trajectory can achieve the lowest energy consumption. ${ }^{(15)}$ The trajectory of a robot arm can be controlled by the working cycle time of the robot arm to optimize the use of energy. ${ }^{(16-22)}$ There have been many attempts to control the trajectory and time from the last working point to the home point of a robot arm in accordance with the standard cycle time with the aim of reducing time and energy consumption. ${ }^{(23,24)}$ In addition to controlling the time and movement path, the results of research on controlling the speed, acceleration, and torque of a motor can also be used to optimize the time for which robot moves. ${ }^{(25,26)}$ Various algorithms for obtaining an optimal condition related to a robot arm have been developed. Particle swarm optimization (PSO) is one of the algorithms used to find optimized values. There are a variety of applications of PSO. One example is the optimal scheduling of the production of thin-film transistors (TFTs), with production capacity allocated by finding the most appropriate production sequence and resolving the bottlenecks of the process occurring in normal production planning. ${ }^{27-30)}$ PSO can be used for the path planning of mobile robots to decide complex paths, such as the paths of 10 mobile robots moving around obstacles. ${ }^{(31)}$

To adjust the conditions to respond to changes, neural networks can be used to find continuous data for rapid adjustment, for example, when designing an application to calculate energy efficiency in home appliances ${ }^{(32)}$ and industry. ${ }^{(33)}$ They have also been used to design wind turbines on a farm ${ }^{(34)}$ and to predict motor trouble to reduce the energy loss resulting from the low efficiency of faulty motors. ${ }^{(35)}$

In industry 4.0, industries will be integrated with the production world owing to network connectivity in the form of the Internet of Things (IoT), which will connect all devices in the production system. A network system will be able to communicate and exchange information from anywhere at any time. As an advantage of industry 4.0, customers should be able to place orders in an application via a phone or computer to control the production cycle time from anywhere. However, a remote-control system for IR to operate at the required time while maintaining the lowest energy consumption has not yet been found. In response to this problem we present a system of remote sensing for controlling a robot arm that can also minimize energy consumption. 


\section{Modeling of Energy Consumption}

For the production system to receive information about customer requirements, the customer must enter the number of required pieces into the system. The quantity of the product required by the customer can be converted to the maximum TackTime of production by

$$
\text { TackTime }=\frac{\text { Working Time }}{\text { Demand }} \text {. }
$$

In Eq. (1), TackTime is the maximum time required for the system to control the speed of the production line. This time is used to determine the speed and acceleration appropriate for movement while using the minimum energy to control the movement of a robot arm. Normally, the production line is designed by the lean manufacturing technique, which focuses on reducing all waste in a production line. However, the energy consumption is not typically considered in the design. Therefore, the energy consumption must be considered in the dynamics of the robot arm, which is determined by the angular coordinates of the robot arm shown in Fig. 1. The movement path can be applied to simulate the trajectory of a robot in a current production system or in the development of a new system.

In each operation, the sum of the energy must be calculated for each path. The energy consumption for the operation is a nonlinear function of the execution time. The same robot also consumes energy while idling after the completion of the operation.

The study of the robot energy is necessary to develop the dynamics of the robot model. A dynamic equation describes the relationship between force and movement. It is important to consider the equation for movement in robot design, including by simulation, to develop an algorithm for control. There are many ways to formulate a dynamic equation of a robot arm. The equation incorporates the force, torque, speed, acceleration, and position.

The torque equation can be expressed as follows, where $q$ is the resulting angle, $\dot{q}$ is speed, and $\ddot{q}$ is acceleration, while the torque must be on the trajectory.

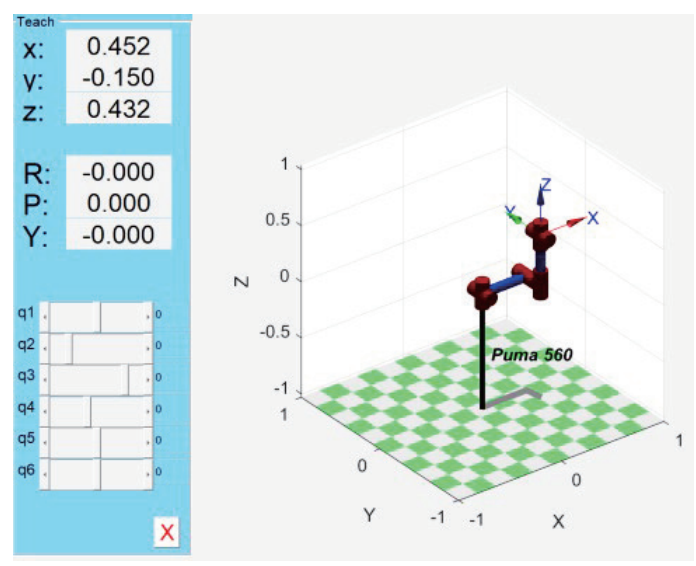

Fig. 1. (Color online) Simulation model of PUMA 560. 


$$
M(q) \ddot{q}+C(q, \dot{q}) \dot{q}+g(q)+\tau_{f}=\tau
$$

The total energy consumption of the path is given by the integral of the absolute value of the product of torque and speed. The power consumed by the robot at any given instance of time is given by

$$
P=|\tau \dot{q}|
$$

Thus, the total energy consumption is

$$
E=\int_{0}^{T}|\tau \dot{q}| d t
$$

Energy can be calculated from the torque and time. Obviously, the energy consumption is related to the speed and acceleration of the robot arm movement, which means that reducing the speed and acceleration can reduce energy consumption.

The study shows that the PSO algorithm can find the optimal solution to most equations, then an appropriate result can be obtained by tuning the obtained solution. The process can obtain the result by considering the following equation:

$$
E=\int_{0}^{T}\left|\left(M(q) \ddot{q}+C(q, \dot{q}) \dot{q}+g(q)+\tau_{f}\right) \times \dot{q}\right| \times d t
$$

From this equation, the energy in joules can be calculated and used as a fitness value in PSO optimization, the flow chart for which is shown in Fig. 2.

The PSO technique can find only one optimal value. In this paper, we propose the use of neural network techniques to find the velocity and acceleration in every period.

As shown in Fig. 3, in the artificial neural network (ANN), all nodes in the input layer send signals to all nodes in the first hidden layer, and all nodes in the first hidden layer send signals to all nodes in the next layer. This is performed until all nodes in the last hidden layer send signals to the nodes in the output layer. The results from such processing will be the output values. Therefore, the values obtained from the ANN will provide the speed and acceleration required in every period to control the robot so that it uses energy efficiently.

\section{Case Study of Energy Optimization}

For industry 4.0, it is necessary to adjust conditions for production in real time. Therefore, we propose the design of a system able to receive a work order from a mobile application and to send data to the production line as shown in Fig. 4.

To adjust the speed and acceleration to reduce energy use in the production system, the program simulation applies a PUMA 560 robot with the D-H parameters in Table 1. Figure 5 shows the dimensions of the robot. 


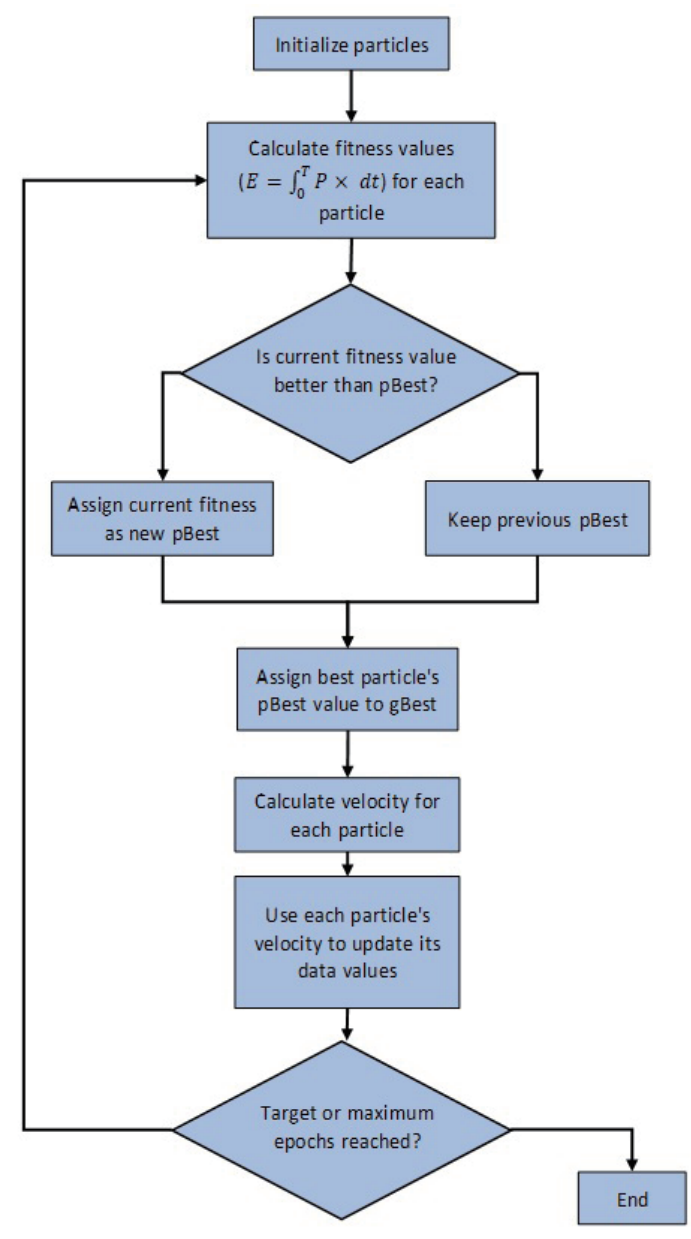

Fig. 2. (Color online) Flow chart for PSO optimization.

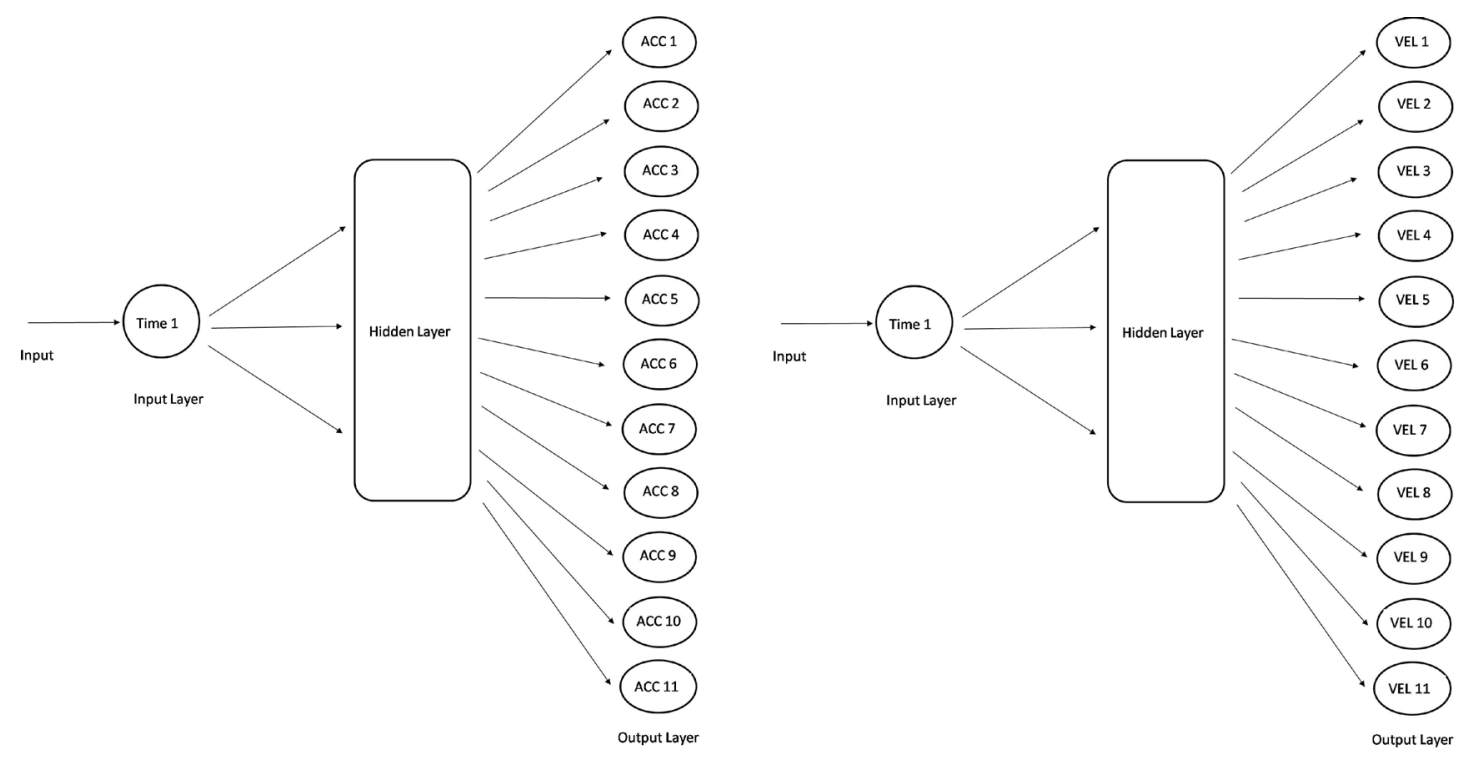

Fig. 3. Diagram of the backpropagation neural network. 


\section{Order Mobile Cloud Control $\Rightarrow$ Robot Out Put}

Fig. 4. (Color online) System diagram for robot remote control.

Table 1

D-H parameters of PUMA 560.

\begin{tabular}{llcl}
\hline Link & $a(\mathrm{~m})$ & $\alpha(\mathrm{rad})$ & $d(\mathrm{~m})$ \\
\hline 1 & 0 & $\pi / 2$ & 0.67 \\
2 & 0.4318 & 0 & 0 \\
3 & 0.4318 & $-\pi / 2$ & 0.1505 \\
4 & 0 & $\pi / 2$ & 0 \\
5 & 0 & $-\pi / 2$ & 0 \\
6 & 0 & 0 & 0.2 \\
\hline
\end{tabular}

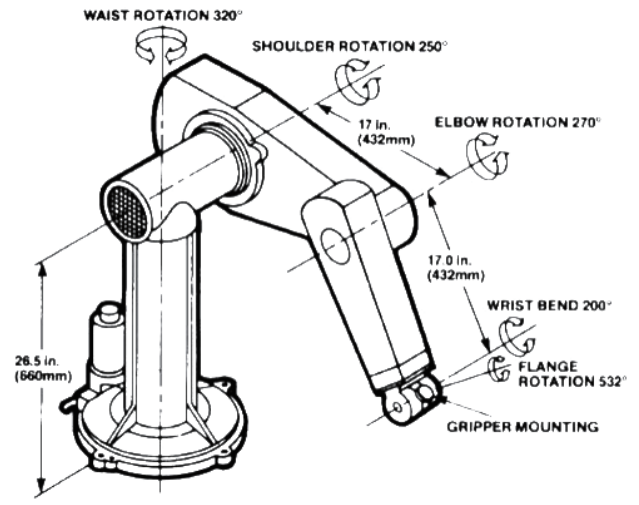

Fig. 5. Dimensions of PUMA 560.

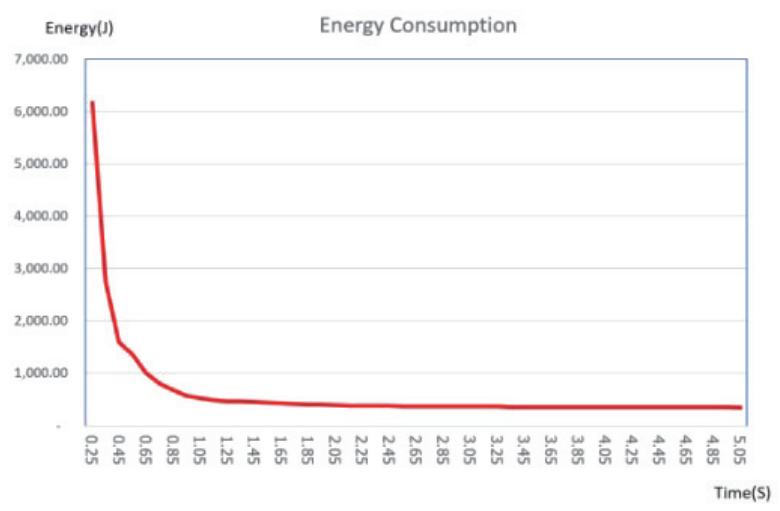

Fig. 6. (Color online) Graph showing relationship between energy consumption and time.

In the simulation of the relationship between energy consumption and time, the robot moves from point $\mathrm{A}$ to point $\mathrm{B}$ and the distance between points $\mathrm{A}$ and $\mathrm{B}$ is set to $100 \mathrm{~mm}$ on the $X$-axis. The starting time of this path is $0.15 \mathrm{~s}$ and the energy consumed by the robot arm is measured at intervals of $0.1 \mathrm{~s}$ up to $5 \mathrm{~s}$. Figure 6 shows the result of the simulation with the same distance between $\mathrm{A}$ and $\mathrm{B}$ but different total times of the trajectory. Lower energy consumption is obtained for longer times, which can be achieved when moving, i.e., when the robot arm moves slowly. The energy consumption can be reduced because the cycle time of each process does not need to change with the minimum cycle time. This is because the robot arm has a waiting time before the next cycle.

The study of the robot to reduce its energy consumption is performed by finding the suitable time, velocity, and acceleration of the moving robot. The initial time of the total trajectory is set to $6.60 \mathrm{~s}$ with a maximum time of the trajectory of $12.09 \mathrm{~s}$ to compare the decrease in energy consumption. 
Figure 7 shows the layout of a process and Figs. 8 and 9 show movement in the simulation and the parameters of PSO with a particle size of 25, 100 iterations, and velocities of 0.3 to 1.0 simulated by MATLAB. The energy from the initial time is presented in Table 2. The data used for training in the neural network simulation obtained from PSO with a period of $1 \mathrm{~s}$ are shown in Table 3.

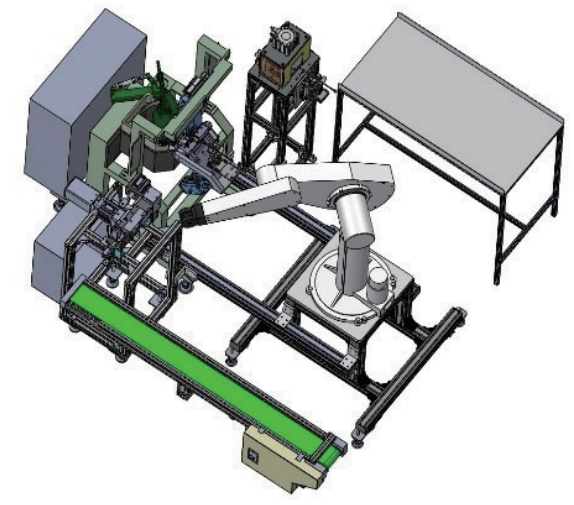

Fig. 7. (Color online) Layout of simulation.

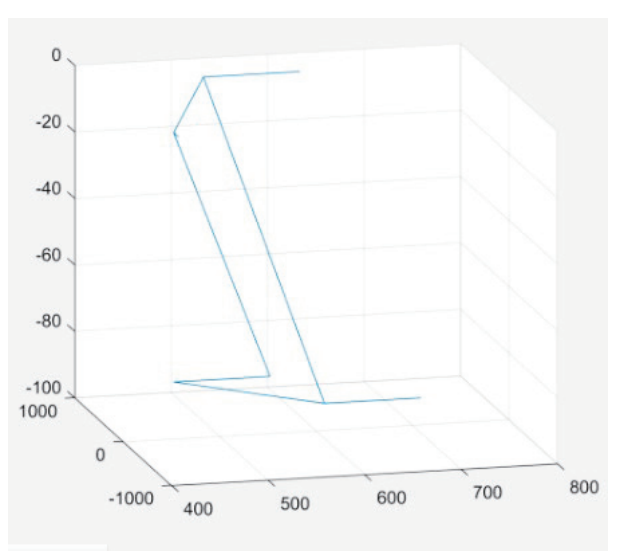

Fig. 8. (Color online) Path used in simulation.

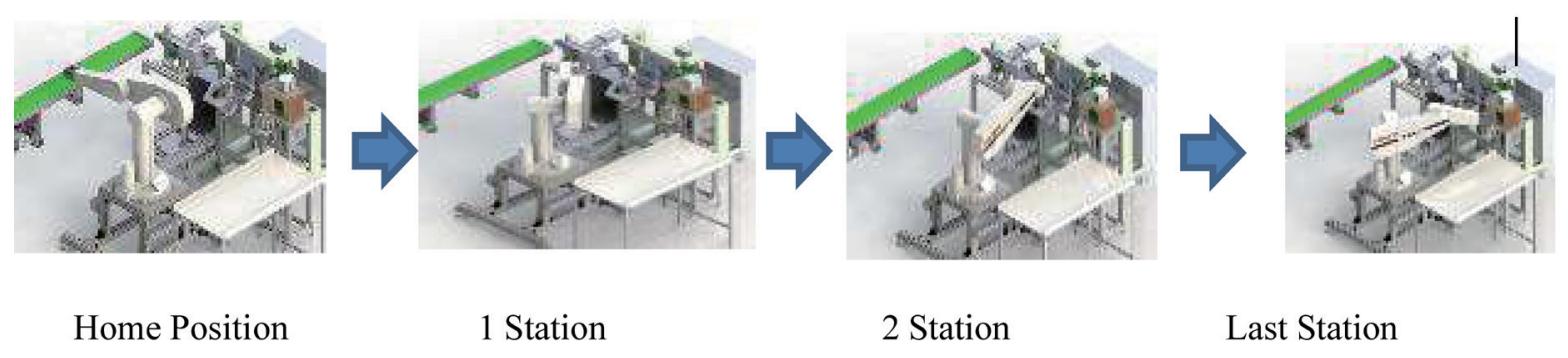

Fig. 9. (Color online) Position of the robot arm when moving to different positions.

Table 2

Position of end effector and energy from the initial time.

\begin{tabular}{lrrrr}
\hline Path & Time & Velocity & Acc. & Energy \\
\hline $1(0.613,0.587,0)$ & 0.30 & 38.78 & 461.60 & 767.70 \\
$2(0.513,0.587,0)$ & 0.30 & 270.79 & 3231.40 & 743.50 \\
$3(0.609,0,-0.092)$ & 1.00 & 10.51 & 33.90 & 1473.20 \\
$4(0.709,0,-0.092)$ & 0.30 & 1.25 & 26.30 & 541.60 \\
$5(0.609,0,-0.092)$ & 0.30 & 2.21 & 26.30 & 542.40 \\
$6(0.424,-0.569,-0.075)$ & 1.00 & 1.89 & 6.10 & 916.20 \\
$7(0.524,-0.569,-0.075)$ & 0.30 & 0.93 & 20.80 & 469.40 \\
$8(0.424,-0.569,0)$ & 0.30 & 1.84 & 21.90 & 324.50 \\
$9(0.0424,-0.569,0)$ & 1.00 & 0.37 & 19.80 & 574.70 \\
$10(0.424,-0.569,0)$ & 0.30 & 2.32 & 27.60 & 600.70 \\
$11(0.513,0.587,0)$ & 1.50 & 2.74 & 8.50 & 1201.30 \\
\hline Total & 6.60 & - & - & 8155.20 \\
\hline
\end{tabular}


Table 3

Data used to train neural network.

\begin{tabular}{|c|c|c|c|c|c|c|c|c|c|c|c|c|}
\hline & Path & Path & Path & Path & Path & Path & Path & Path & Path & Path & Path & $\begin{array}{l}\text { Total } \\
\text { time }\end{array}$ \\
\hline & 1 & 2 & 3 & 4 & 5 & 6 & 7 & 8 & 9 & 10 & 11 & \\
\hline Time & 0.45 & 0.87 & 2.11 & 0.41 & 0.30 & 1.98 & 0.49 & 0.73 & 0.67 & 0.73 & 2.60 & 11.34 \\
\hline Velocity & 26.30 & 97.07 & 4.86 & 0.93 & 2.21 & 0.92 & 0.63 & 0.76 & 0.56 & 0.96 & 1.55 & \\
\hline Acc. & 176.09 & 359.04 & 7.23 & 12.23 & 26.32 & 1.45 & 7.93 & 3.23 & 47.03 & 4.07 & 2.73 & \\
\hline Time & 0.67 & 0.83 & 1.88 & 0.30 & 0.30 & 1.85 & 0.83 & 0.35 & 0.47 & 0.43 & 2.17 & 10.09 \\
\hline Velocity & 18.81 & 104.94 & 5.44 & 1.25 & 2.21 & 0.98 & 0.36 & 1.67 & 0.79 & 1.73 & 1.87 & \\
\hline Acc. & 94.05 & 413.06 & 9.09 & 26.32 & 26.32 & 1.63 & 2.66 & 14.70 & 88.05 & 12.85 & 4.01 & \\
\hline Time & 0.53 & 0.45 & 1.82 & 0.43 & 0.34 & 1.98 & 0.51 & 0.46 & 0.57 & 0.47 & 1.70 & 9.26 \\
\hline Velocity & 22.80 & 183.64 & 5.62 & 0.93 & 2.00 & 0.92 & 0.55 & 1.25 & 0.63 & 1.57 & 2.37 & \\
\hline Acc. & 142.50 & 1232.70 & 9.70 & 12.20 & 17.60 & 1.40 & 6.40 & 8.40 & 57.70 & 10.50 & 6.40 & \\
\hline Time & 0.61 & 0.52 & 1.78 & 0.32 & 0.30 & 1.30 & 0.43 & 0.43 & 0.37 & 0.47 & 1.72 & 8.25 \\
\hline Velocity & 21.04 & 159.23 & 5.79 & 1.25 & 2.21 & 1.40 & 0.69 & 1.37 & 1.05 & 1.57 & 2.37 & \\
\hline Acc. & 115.41 & 997.56 & 10.26 & 26.32 & 26.32 & 3.36 & 9.66 & 10.20 & 154.60 & 10.54 & 6.41 & \\
\hline Time & 0.36 & 0.44 & 1.45 & 0.30 & 0.30 & 1.35 & 0.46 & 0.30 & 0.42 & 0.30 & 1.44 & 7.13 \\
\hline Velocity & 35.06 & 201.39 & 7.18 & 1.25 & 2.21 & 1.35 & 0.63 & 1.84 & 0.86 & 2.32 & 2.84 & \\
\hline Acc. & 309.20 & 1502.00 & 15.80 & 26.30 & 26.30 & 3.10 & 7.90 & 21.90 & 107.30 & 27.60 & 9.20 & \\
\hline Time & 0.39 & 0.65 & 0.96 & 0.30 & 0.30 & 1.00 & 0.42 & 0.46 & 0.52 & 0.35 & 0.97 & 6.34 \\
\hline Velocity & 35.06 & 131.36 & 10.51 & 1.25 & 2.21 & 1.89 & 0.69 & 1.25 & 0.68 & 2.10 & 4.16 & \\
\hline Acc. & 309.19 & 658.36 & 33.90 & 26.32 & 26.32 & 6.09 & 9.66 & 8.37 & 71.25 & 18.51 & 19.81 & \\
\hline Time & 0.45 & 0.39 & 1.00 & 0.30 & 0.32 & 0.99 & 0.30 & 0.34 & 0.31 & 0.37 & 0.98 & 5.76 \\
\hline Velocity & 26.30 & 244.85 & 10.51 & 1.25 & 2.21 & 1.89 & 0.93 & 1.67 & 1.16 & 2.10 & 4.16 & \\
\hline Acc. & 176.10 & 2164.30 & 33.90 & 26.30 & 26.30 & 6.10 & 20.80 & 14.70 & 230.80 & 18.50 & 19.80 & \\
\hline Time & 0.30 & 0.30 & 0.84 & 0.30 & 0.30 & 0.74 & 0.30 & 0.30 & 0.30 & 0.33 & 0.93 & 4.94 \\
\hline Velocity & 38.78 & 270.79 & 11.89 & 1.25 & 2.21 & 2.46 & 0.93 & 1.84 & 1.16 & 2.32 & 4.45 & \\
\hline Acc. & 461.60 & 3231.40 & 43.90 & 26.30 & 26.30 & 10.50 & 20.80 & 21.90 & 230.80 & 27.60 & 22.40 & \\
\hline
\end{tabular}
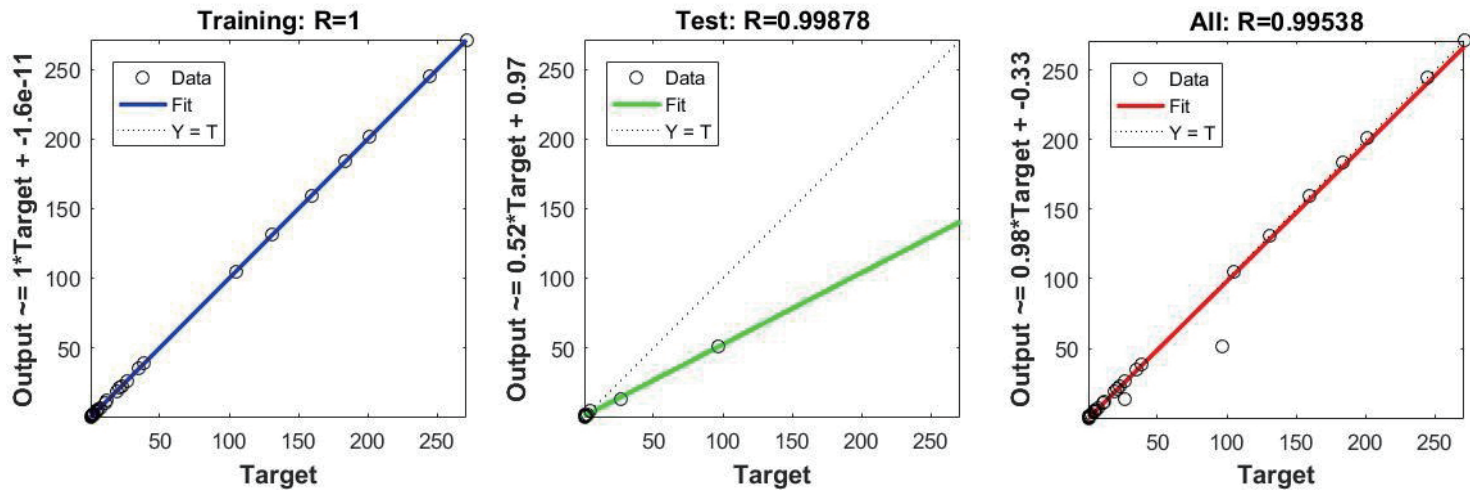

Fig. 10. (Color online) Regression between actual output and the output obtained by the proposed neural network.

Figure 10 shows the lines of best fit between the actual output and the output obtained with the proposed neural network. The correlation coefficient $R$ between the actual output and the training result was 1 and that between the training result and the actual data was 0.9988 . The system calculates the speed, acceleration, and energy of the most suitable movements of the robotic arm. 


\section{Results}

MATLAB is applied to optimize the energy consumption resulting from moving the robot arm. Figure 11 shows the number of iterations with different fitness values. Table 4 shows the minimum energy consumption obtained by PSO. This method reduces energy consumption from 8155.20 to $7148.6 \mathrm{~J}$, a decrease of $12.3 \%$. On the other hand, the total moving time is increased by $71.8 \%$ from 6.60 to $11.34 \mathrm{~s}$.

After applying an ANN, the data obtained from PSO creates continuous data of angular velocity and acceleration (Fig. 12). To minimize the energy consumed by the robot arm, the ANN provides the acceleration and speed for different cycle times.

When entering the cycle time into the system, the system correctly calculated the speed and acceleration. The time required by the PSO technique to obtain the optimal value was $1690.80 \mathrm{~s}$ in addition to the $2 \mathrm{~s}$ required by the neural network. This means that the time will be reduced significantly when an order is entered from a remote controller.

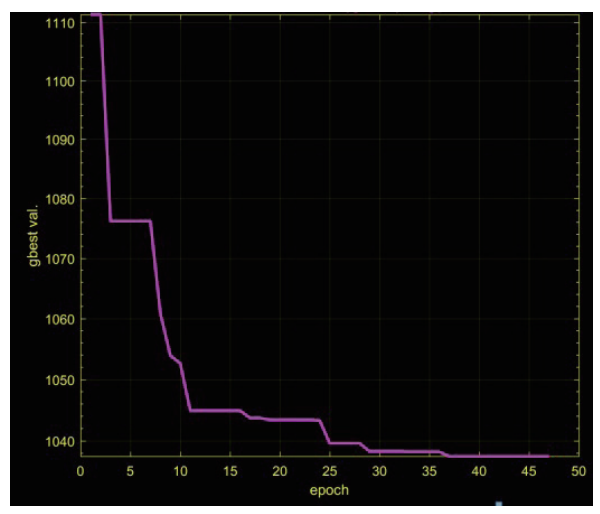

Fig. 11. (Color online) Number of iterations with different fitness values.

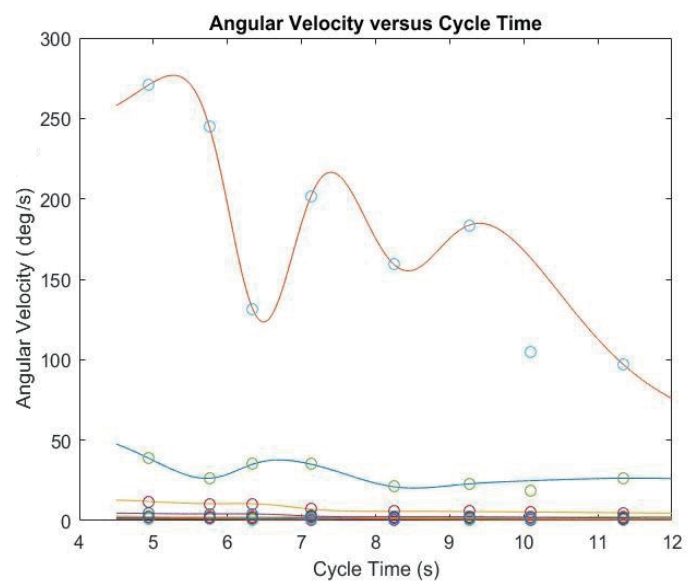

(a)
Table 4

Minimum energy consumption obtained from PSO.

\begin{tabular}{lrcrr}
\hline Path & Time & Velocity & \multicolumn{1}{c}{ Acc. } & \multicolumn{1}{c}{ Energy } \\
\hline $1(0.613,0.587,0)$ & 0.45 & 26.30 & 176.09 & 758.10 \\
$2(0.513,0.587,0)$ & 0.87 & 97.07 & 359.04 & 734.80 \\
$3(0.609,0,-0.092)$ & 2.11 & 4.86 & 7.23 & 1200.10 \\
$4(0.709,0,-0.092)$ & 0.41 & 0.93 & 12.23 & 531.00 \\
$5(0.609,0,-0.092)$ & 0.30 & 2.21 & 26.32 & 542.40 \\
$6(0.424,-0.569,-0.075)$ & 1.98 & 0.92 & 1.45 & 635.40 \\
$7(0.524,-0.569,-0.075)$ & 0.49 & 0.63 & 7.93 & 461.80 \\
$8(0.424,-0.569,0)$ & 0.73 & 0.76 & 3.23 & 308.80 \\
$9(0.0424,-0.569,0)$ & 0.67 & 0.56 & 47.03 & 566.60 \\
$10(0.424,-0.569,0)$ & 0.73 & 0.96 & 4.07 & 567.60 \\
$11(0.513,0.587,0)$ & 2.60 & 1.55 & 2.73 & 842.00 \\
\hline Total & 11.34 & - & - & 7148.60 \\
\hline
\end{tabular}

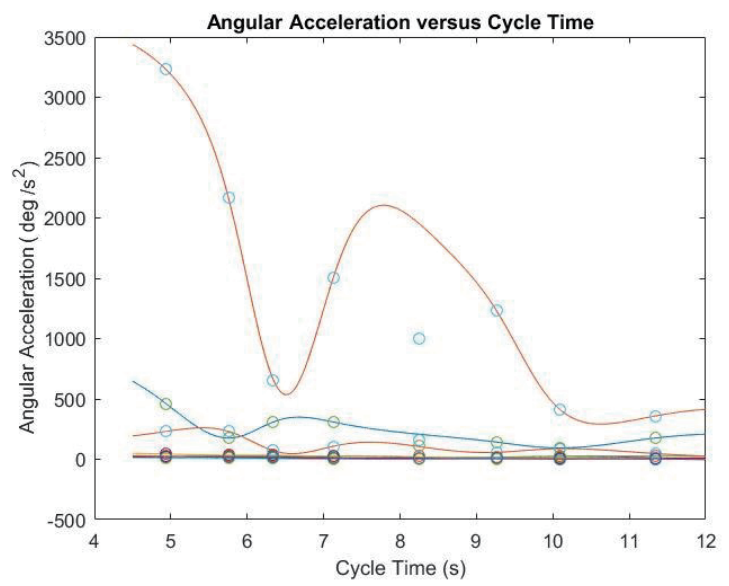

(b)

Fig. 12. (Color online) Continuous data of (a) velocity and (b) acceleration obtained from the neural network. 


\section{Conclusion}

Because of the widespread use of robot arms in industry, the cost of the energy consumed by them is significant. We present a new method of remote control to adjust production in real time by using energy optimization techniques to maximize the efficiency of remotecontrol production orders. By applying IoT technology, our method can control a robot arm by adjusting its speed while minimizing its energy consumption. Our method can be applied to smart factories to obtain the most effective time and minimize energy consumption when receiving orders from a distance.

\section{Acknowledgments}

This work was supported by Thailand Research Fund and NSTDA.

\section{References}

1 R. Muslimen, S. Yusof, and A. Abidin: 2011 World Congress on Engineering (WCE, 2011), Vol. I. https://ir.unimas.my/id/eprint/13996/1/A\%20case\%20study \%20of\%20Lean\%20Manufacturing \%20 Implementation\%20Approach\%20in\%20Malaysian\%20Automotive\%20Components\%20Manufacturer.pdf

2 D. B. Modi and H. Thakkar: Int. J. Emerging Technol. Adv. Eng. 4 (2014) 339. https://pdfs.semanticscholar. org/8f25/5854b85da898d368c79ae2b8daeed9a65e16.pdf

3 S. Wang, J. Wan, D. Li, and C. Zhang: Int. J. Distrib. Sens. Netw. 2016 (2016) 1. https://journals.sagepub.com/ doi/full/10.1155/2016/3159805

4 J. Posada, C. Toro, I. Barandiaran, and D. Oyarzun: IEEE Comput. Graphics Appl. 35 (2015) 26. https:// ieeexplore.ieee.org/document/7064655

5 P. Robison, M. Sengupta, and D. Rauch: IT Prof. 17 (2015) 17. https://ieeexplore.ieee.org/document/7116423

6 X. Zhou, H. Yan, J. Wang, and Y. Wang: IEEE Int. Conf. Enterprise Systems (2017) 331. https://ieeexplore. ieee.org/document/8119412

7 M. Unterhofer, E. Rauch, D. T. Matt, and S. Santiteerakul: IEEE Int. Conf. Industrial Engineering and Engineering Management (IEEM) (2018) 720. https://ieeexplore.ieee.org/document/8607445

8 P. Gamba, E. Goldoni, P. Savazzi, P. G. Arpesi, C. Sopranzi, J. F. Dufour, and M. Lavagna: IEEE Sens. J. 14 (2011) 3883. https://ieeexplore.iee.org/document/6888464

9 W. C. Huang, G. Zhang, and D. Li: IEEE Trans. Geosci. Remote Sens. 54 (2016) 4355. https://ieeexplore.ieee. org/document $/ 7446303$

10 P. Angove, M. O’Grady, J. Hayes, and B. O’Flynn: IEEE Sens. J. 11 (2011) 3309. https://ieeexplore.ieee.org/ document $/ 5871997$

11 E. A. Abdelaziz, R. Saidura, and S. Mekhilef: Renewable Sustainable Energy Rev. 15 (2011) 150.

12 D. Meike and L. Ribickis: 15th IEEE Int. Conf. Advanced Robotics (ICAR) (2011) 507. https://ieeexplore.ieee. org/document/6088567

13 O. Maimon, E. Profeta, and S. Singer: J. Intell. Rob. Syst. 4 (1991) 175. https://link.springer.com/ article/10.1007/BF00440418

14 E. S. Sergaki, G. S. Stavrakaki, and A. D. Pouliezo: J. Intell. Rob. Syst. 33 (2020) 187. http://pouliezos.dpem. tuc.gr/pdf/JIRS_2002.pdf

15 J. S. Park: Mechatronics 6 (1996) 649. https://fdocuments.in/document/motion-profile-planning-of-repetitivepoint-to-point-control-for-maximum-energy.html

16 J. Yao, W. Gu, Z. Feng, L. Chen, Y. Xu, and Y. Zhao: Rob. Comput. Integr. Manuf. 48 (2017) 51. https://www. sciencedirect.com/science/article/abs/pii/S0736584516300278

17 A. Vergnano, C. Thorstensson, B. Lennartson, P. Falkman, M. Pellicciari, C. Yuan, S. Biller, and F. Leali: IEEE Conf. Automation Science and Engineering (2010) 386. https://ieeexplore.ieee.org/document/5584686

18 O. Wigström, B. Lennartson, A. Vergnano, and C. Breitholtz: IEEE Trans. Autom. Sci. Eng. 10 (2013) 57. https://ieeexplore.ieee.org/document/6204092 
19 H. Lyu, X. Song, D. Dai, J. Li, and Z. Li: 13th IEEE Conf. Automation Science and Engineering (CASE) (2017) 503. https://ieeexplore.ieee.org/document/8256154

20 S. Pellegrinelli, S. Borgia, N. Pedrocchi, E. Villagrossi, G. Bianchi, and L. M. Tosatti: Proc. CIRP 29 (2015) 354. https://www.sciencedirect.com/science/article/pii/S2212827115004886

21 R. Ur-Rehman, S. Caro, D. Chablat, and P. Wenger: Can. Soc. Mech. Eng. 33 (CSME, 2009) 523. https://www. nrcresearchpress.com/doi/abs/10.1139/tcsme-2009-0035

22 P. Cezner: Robotic Trajectory Optimization, Czech Technical University in Prague, Syst. and Control (May 2017). https://support.dce.felk.cvut.cz/mediawiki/images/4/4f/Bp_2017_cezner_petr.pdf

23 D. Meike, M. Pellicciari, and G. Berselli: IEEE Trans. Autom. Sci. Eng. 11 (2014) 798. https://ieeexplore.ieee. org/document $/ 6668986$

24 Y. L. Hsu, M. S. Huang, and R. F. Fung: 6th IFAC Symp. Mechatronic Syst. 24 (2013) 628. https://www. researchgate.net/publication/259519035_Energy-saving_trajectory_planning_for_a_toggle_mechanism_ driven_by_a_PMSM

25 Y. Zhang and J. Wang: IEEE Trans. Syst., Man, Cybern. (2002) 654. https://ieeexplore.ieee.org/ document/1033184

26 H. Du, J. M. Du, L. A. Chen, Z. W. Mai, and X. H. Liu: Int. Conf. Artificial Intelligence and Industrial Eng. (2015) 345. https://www.atlantis-press.com/proceedings/aiie-15/22139

27 P. Pongchairerks: Asia Pac. J. Oper. Res. 26 (2009) 161. https://www.researchgate.net/publication/46510351_ A_particle_swarm_optimization_algorithm_on_job-shop_scheduling_problems_with_multi-purpose_ machines

28 Y. Y. Chen: Int. Multi Conf. Engineering and Computer Scientists 2010 (IMCES, 2010). http://www.iaeng.org/ publication/IMECS2010/IMECS2010_pp1791-1796.pdf

29 Y. Guo, W. Li, A. R. Mileham, and G. W. Owen: Int. J. Prod. Res. 14 (2009) 3775. https://hal.archivesouvertes.fr/hal-00513021/document

30 P. Pongchairerks: Sci. Asia 35 (2009) 89. http://www.scienceasia.org/2009.35.n1/scias35_89.pdf

31 A. Ayar and S. Bouamama: IEEE Int. Conf. Real-Time Computing and Robotics (2017) 437. https://ieeexplore. ieee.org/document/8311901

32 C. Zhou, S. Liu, and P. Liu: 3rd IEEE Int. Conf. Information Science and Control Engineering (2016) 483. https://ieeexplore.ieee.org/document/7726207

33 L. Wei and S. Yumin: IEEE Int. Symp. Knowledge Acquisition and Modeling Workshop (2008) 176. https:// ieexplore.ieee.org/document/4810454

34 M. C. Mabel and E. Fernandez: IEEE Trans. Energy Convers. 24 (2009) 459. https://ieeexplore.ieee.org/ document $/ 4738388$

35 L. F. Tsai, Y. T. Ku, Y. C. Chang, and H. L. Chung: IEEE Int. Conf. Computer Engineering and Technology (2009) 548. https://ieeexplore.ieee.org/document/4769663

\section{About the Authors}

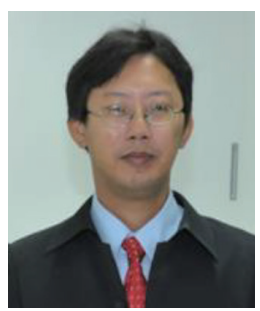

Somyot Kaitwanidvilai received his B.Eng and M.Eng degrees in electrical engineering from King Mongkut's Institute of Technology Ladkrabang (KMITL), Thailand, in 1996 and 2000, respectively. He received his Ph.D. degree in mechatronics engineering from the Asian Institute of Technology in 2005. Currently, he works at KMITL in the Department of Electrical Engineering. His research interests include artificial intelligence in power and energy systems, control systems, mechatronics, power electronics, and robust and adaptive control in power systems. (somyot.ka@kmitl.ac.th) 


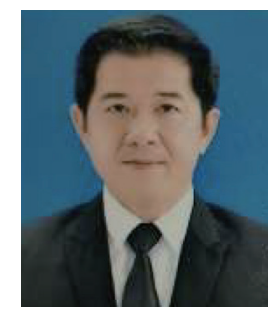

Veerasak Chanarungruengkij received his B.Eng degree in material handling technology from King Mongkut's Institute of Technology North Bangkok (KMITNB), Thailand, in 1997. He received his M.Eng degree in information and system engineering from King Mongkut's Institute of Technology Ladkrabang (KMITL) Thailand, in 2017. Currently, he is studying for a Ph.D. degree in electrical engineering at KMITL. His research interests include artificial intelligence in energy systems, control systems, mechatronics, and robotics technology. (vee7713@gmail.com)

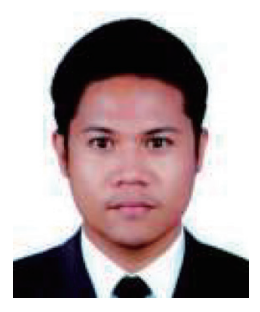

Poom Konghuayrob received his B.Eng and M.Eng degrees in electrical engineering from King Mongkut's Institute of Technology Ladkrabang (KMITL), Bangkok, Thailand, in 2012 and 2013, respectively. He is currently working towards a Ph.D. degree in electrical engineering at KMITL. His research interests are in the areas of robust control, DC/AC inverters, solar cell fields, and artificial intelligence. (poom.konghuayrob@gmail.com) 